\title{
Whole genome sequence analysis of multi drug resistant community associated methicillin resistant Staphylococcus aureus from food fish: Detection of clonal lineage ST 28 and its antimicrobial resistance and virulence genes
}

Gopalan Krishnan Sivaraman ${ }^{\text {Corresp., } 1}{ }^{\text {, Visnuvinayagam Sivam }}{ }^{1}$, Balasubramanian Ganesh ${ }^{2}$, Ravikrishnan Elangovan ${ }^{3}$, Ardhra Vijayan ${ }^{4}$, Mukteswar Prasad Mothadaka ${ }^{4}$

${ }^{1}$ Microbiology, Fermentation \& Biotechnology,, ICAR- Central Institute of Fisheries Technology, COCHIN, Kerala, India

2 Division of Laoratory, ICMR- National Institute of Epidemiology, Chennai, Tamil Nadu, India

3 Biochemical Engineering and Biotechnology, Indian Institute of Technology, Delhi, Delhi, Delhi, India

4 Microbiology, Fermentation \& Biotechnology, ICAR- Central Institute of Fisheries Technology, COCHIN, KERALA, India

Corresponding Author: Gopalan Krishnan Sivaraman

Email address: gkshivraman@gmail.com

Methicillin-resistant staphylococcus aureus (MRSA) sequence type 28 (ST 28) and spa type t021 is a CC30, prototype of ST-30, Community Associated-MRSA (CA-MRSA) (lukS-lukF +). It is a multi-drug resistant strain harbouring staphylococcal endotoxins, haemolysins, ureolysin, serine protease, and antimicrobial resistance genes. In this study, we report the draft genome sequence of this MRSA isolated from the most commonly used food fish, Ribbon fish,Trichiurus lepturus. The total number of assembled paired-end high-quality reads was $7,731,542$ with a total length of $\sim 2.8 \mathrm{Mb}$ of 2797 predicted genes. The unique ST28/ t021 CA- MRSA in fish is the first report from India, and in addition to antibiotic resistance is known to co-harbour virulence genes, haemolysins, aureolysins and endotoxins. Comprehensive comparative genomic analysis of CA-MRSA strain 7 can help further understand their diversity, genetic structure, diversity and a high degree of virulence to aid in fisheries management. 
1

2 Title: Whole Genome Sequence analysis of Multi Drug Resistant Community Associated

5

6 G. K. Sivaraman ${ }^{1 *}$, Visnuvinayagam $\mathbf{S}^{1}$, Balasubramanian Ganesh ${ }^{2}$, Ravikrishnan

7 Elangovan $^{3}$, Ardhra Vijayan ${ }^{1}$, and Mukteswar P. Mothadaka ${ }^{1}$

\section{8 and its antimicrobial resistance and virulence genes}

${ }^{1}$ Microbiology, Fermentation and Biotechnology Division, Indian Council of Agricultural

Research-Central Institute of Fisheries Technology, Kochi, Kerala, India.

${ }^{2}$ ICMR- National Institute of Epidemiology, Chennai, Tamil Nadu, India.

${ }^{3}$ Department of Biochemical Engineering and Biotechnology, Indian Institute of Technology (IIT), Delhi, India.

\section{*Corresponding Author:}

Dr. G. K. Sivaraman

Willingdon Island, Cochin-682029, Kerala State, India.

E-mail:gkshivraman@gmail.com

gk.sivaraman@icar.gov.in

\begin{abstract}
Methicillin-Resistant Staphylococcus aureus (MRSA) sequence type 28 (ST 28) and spa type t021 is a CC30, prototype of ST-30, Community Associated-MRSA (CA-MRSA) (lukS-lukF +). It is a multi-drug resistant strain harbouring staphylococcal endotoxins, haemolysins, ureolysin, serine protease, and antimicrobial resistance genes. In this study we report the draft genome sequence of this MRSA isolated from most commonly used food fish, Ribbon fish, Trichiurus lepturus. The total number of assembled paired-end high-quality reads was $7,731,542$ with a total length of $\sim 2.8 \mathrm{Mb}$ of 2797 predicted genes. The unique ST28/ t021 CA- MRSA in fish is the first report from India, and in addition to antibiotic resistance is known to co-harbour virulence genes, haemolysins, aureolysins and endotoxins. Comprehensive comparative genomic analysis of CA-MRSA strain7 can help further understand their diversity, genetic structure, diversity and a high degree of virulence to aid in fisheries management.
\end{abstract}

Subjects Microbiology, Biotechnology, Epidemiology 
32 Keywords Whole genome sequence; Community Associated MRSA; Virulence genes;

33 Antimicrobial resistance genes; Seafood

34

\section{INTRODUCTION}

Staphylococcus aureus is a well-known human pathogen and causes nosocomial, community-acquired infections in humans and animals, and food intoxication. Methicillinresistant S. aureus (MRSA) is a common, and growing cause of nosocomial and communityacquired infections in human, and livestock associated MRSA (LA-MRSA) in animals. The severity of disease is due to the genetic structure of the organismviz., phenotypic, genotypic, virulence pattern, antimicrobial resistance genes and toxin genes etc. During the past three decades, the Community Associated-MRSA (CA-MRSA) is continuously growing worldwide (Raygada \& Levine, 2009). CA-MRSA indicates existing in a community set up, susceptibility to non-beta lactam antibiotics, harbours Staphylococcal Cassette Chromosome mec (SCCmec) cassettes IV or $\mathrm{V}$ and positives for Panton Valentine leucocidin toxin genes (PVL). Several reports are available on the spread of CA-MRSA within households/among family members by close personal contact and acts as potential reservoirs (Jones et al., 2006,Nerby et al., 2011,Knox et al., 2012). Its virulence is controversial based on the presence or lack of gene deletions in PVL in different animal models and human but the exact role of PVL in the CA-MRSA epidemic is debatable (Li et al., 2010, Diep et al., 2010, DeLeo et al., 2011). The core- genome virulence factors such as alpha toxin, accessory gene regulator (agr), skin and soft tissue infections (SSTI), and its nature of invasive infections are responsible for its virulence (Novick \& Muir, 1999, Risson et al., 2007, Wang et al., 2007, Wardenburg et al., 2007, Queck et al., 2008, Li et al., 2010, DeLeo et al., 2011,Coombs et al., 2012). More recently, additional antimicrobial resistance genes (ARGs) such as msrA, tetK, etc., also contribute for the severity of CA-MRSA virulence. Latest reports indicate the spread, diversification and steady increase in antibiotic resistance (Coombs et al., 2009, Talan et al., 2011). The prospect of multi drug resistance with increased virulence is of great concern. Moreover, Staphylococci is not a normal host of fish but its presence on fish may be attributed mainly due to contamination from the natural waterbodies where its growing, poor personnel hygiene at different level of handling from pond to plate. Hence, the presence of ST28/ st021 CA-MRSA has become a major public health threat due to its presence in the food fishes, and which can possess highly virulent genes and multidrug 
63 resistance. Moreover, the presence of co-harbouring ARGs such as $m e p \mathrm{R}, m g r \mathrm{~A}$, $\operatorname{ar} l \mathrm{R}, \operatorname{lm} r \mathrm{~S}$, 64 fos $\mathrm{B}$, nor A and $g l p \mathrm{~T}$ and murA transferase in the CA-MRSA have not yet been reported based 65 on whole genome sequencing from fish in India. In the present investigation, the draft genome 66 sequence of $l u k \mathrm{~S}-l u k \mathrm{~F}$ MRSA strain 7 isolated from the fish highlighting its genetic structure.

\section{MATERIALS AND METHODS}

68

\section{Fish samples collection}

The MRSA strain7 isolated from Trichiurus lepturus (Ribbon fish), a sea caught fish of Veraval, Gujarat, India. This sun dried fish is supplied to local markets and other parts of India mainly to North Eastern states and neighbouring countries.

\section{Isolation, identification and antimicrobial susceptibility testing (AST) of S. aureus} ISO 6888-1 and ISO 6888-2:2003 (ISO, 2003) was followed for the isolation and identification of $S$. aureus from the fish samples. In brief, $10 \mathrm{~g}$ of samples were homogenized in sterile Normal Saline and 0.3, 0.3 and $0.4 \mathrm{ml}$ was poured on to Baird Parker Agar (BPA) plate after making the serial dilution. Characteristic colonies of $S$. aureus were purified and streaked onto Brain Heart Infusion (BHI) agar slant for further confirmation on the readymade MRSA plates BBL CHROMagar MRSA II (BBL, Difco).AST was carried out by disc diffusion method as per CLSI guidelines (CLSI, 2018) with 24 antibiotics (Dodeca Staphylococci-1 and 2, HiMedia, Mumbai) Mueller Hinton agar supplemented with $4 \% \mathrm{NaCl}$ were used for the test.The inhibition zones were measured and to find the sensitivity and resistant. S. aureus ATCC 25923 and ATCC 43300 were used as reference strains in this study.

\section{DNA isolation and identification MRSA by triplex PCR}

DNA isolation was carried out using GenElute Bacterial Genomic DNA Kit (Sigma- Aldrich, Spain). The Multiplex PCR was carried out (Al-Talib et al., 2009) for simultaneous detection of S. aureus and MRSA with mec $A$ (mecA- F: ACGAGTAGATGCTCAATATAA, mecA-R: CTTAGTTCTTTAGCGATTGC, 293bp), fem $A$ gene (femA-F: CGATCCATATTTACCATATCA, femA-R: ATCACGCTCTTCGTTTAGTT, 450bp) and 16SrRNA primer specific to Staphylococcus genes specific detection (16S rRNA-F: GCAAGCGTTATCCGGATTT, 16S rRNA-R: CTTAATGATGGCAACTAAGC, 597bp) and were Sanger sequenced for the confirmation. $50 \mu \mathrm{l}$ of reaction mixture contained $200 \mu \mathrm{M}$ 
$92 \mathrm{dNTPs}, 2.5 \mathrm{mM} \mathrm{MgCl}_{2}$, 1X PCR buffer, 0.5U Tag DNA polymerase (Sigma, Spain), $100 \mu \mathrm{g}$ $93 \mathrm{DNA} / \mu 1$ with primer concentration of $0.6 \mathrm{pmol} 16 \mathrm{~S}$ rRNA, $0.8 \mathrm{pmolnuc}$, and $1.0 \mathrm{pmol}$ mecA. 94 The reaction was carried out using SureCycler 8000 (Agilent, USA) with initial denaturation at $9594^{\circ} \mathrm{C}(3 \mathrm{~min}) 34$ cycles of denaturation at $94^{\circ} \mathrm{C}(30 \mathrm{sec})$, annealing at $60^{\circ} \mathrm{C}(30 \mathrm{sec})$, extension at $9672^{\circ} \mathrm{C}(30 \mathrm{sec})$ and a final extension at $72^{\circ} \mathrm{C}(5 \mathrm{~min})$ and electrophoresis on $1.5 \%$ agarose gels 97 with ethidium bromide in Gel Doc (BioRad, USA) (Supplementary Fig.S1).

\section{Whole Genome Sequencing and data Analysis}

The genomic DNA was isolated by bacterial genomic DNA isolation kit (Sigma-Aldrich, France), and its quality was checked on a NanoDrop. The whole-genome sequencing was carried out in IlluminaHiSeq 2500(paired end) (Illumina Inc., Cambridge, UK)and was assembled to determine the genetic structure and its multiple drug resistance.

The number of paired-end reads was approximately 7 billion short-read sequences in pairs of $\sim 300 \mathrm{bp}$, the number of bases $(\mathrm{Mb})$ was 650.26 , and there was $35.28 \% \mathrm{G}+\mathrm{C}$ content. De novo contig assembly was performed using MaSuRCA (Gutierrez et al., 2012), and further downstream processing was performed. Coding sequences (CDSs) were predicted from the contigs using Glimmer (Zimin et al., 2013), and 2,693 predicted CDSs were found. Organism annotation, gene and protein annotation to the matched genes, gene ontology annotation, and pathway annotation were carried out with the use of the NCBI database. Overall, we observed that 2,669 (99.10\%) of the predicted CDSs had at least one hit in the NCBI database. Among the total significant BLASTX hit CDSs, 1,703 genes were annotated using the UniProt database. The total number of Gene Ontology annotations identified for molecular functions was 889, with 604 annotations having to do with a biological process and 236 annotations having to do with cellular components. We predicted tRNA genes from the contigs using tRNAscan-SE (Delcher et al., 1999) and found 70 genes and the detailed analysis of the WGS are provided in the Sivaraman et al., 2017.

\section{Spa typing, Multilocus sequence typing (MLST), and prediction of virulence and}

\section{antimicrobial genes}

The spa typing, MLST analysis and VirulenceFinder2.0 of the MRSA was done by comparing the WGS of the MRSA using the Center for Genomic Epidemiology (http://www.genomicepidemiology.org/) (Larsen et al., 2012)where in raw sequencing reads are 
122 uploaded KMA is used for mapping Illumina sequencing platforms. The database includes

123 following genes: hlb, hlgABC, tst, lukED, lukFS-PV, etAB, edinABC, aur, splABE, scn, sak, 124 ACME and enterotoxins A-E, G-O, R, U, Q. The ARGs detection by The Comprehensive 125 Antibiotic Resistance database (CARD) by Protein homolog criteria (Alcock et al., 2020).

\section{RESULTS AND DISCUSSION}

\section{Whole genome of CA- MRSA Strain}

128 The draft genome of a CA-MRSA strain7 contains 7,731,542 number of reads and 731,267,948 129 bases assembled into 120 contigs, $35.11 \% \mathrm{G}+\mathrm{C}, 80$ tRNAs with the NCBI Accession Number 130 NBZX00000000.1 (BioProject: PRJNA352109; BioSample: SAMN05967212), the N50 estimate 131 was $66022 \mathrm{bp}$. It contained an average scaffold of $23759.70 \mathrm{bp}$, largest scaffold of $170965 \mathrm{bp}$ and 132 smallest of $301 \mathrm{bp}$. The predicted and annotation of the genome (NCBI Prokaryotic Genome 133 Annotation Pipeline) shows 2797 coding sequences (CDSs) and the number of predicted 134 CDSwith significant BLASTX match was 2755, number of predicted CDs with UniProt 135 annotation was 1741 . We observed that $100 \%$ of the predicted CDSs have a similarity of more 136 than $60 \%$ at the 237 protein level with the existing proteins at the NCBI database. The majority 137 of the top BLASTX hits 238 belonged to Staphylococcus species (top 15 organisms). The average 138 gene size of 902, longest gene of 30258 and shortest gene of $72 \mathrm{bp}$ in length (Supplementary 139 Table S1 and S2). The gene ontology sequence distribution of MRSA7 strain contributed 51\%, $14035 \%$ and $14 \%$ towards molecular functions, biological process and cellular components, 141 respectively (Fig.1 and Supplementary Excel data file and Supplementary Figure 3). The 142 molecular and biological process has almost equally made up the majority of the GO 143 annotations, followed by cellular components. The subcategories like 'metabolic process' and 144 'cellular process' are in the cluster of biological process; two sub categories 'binding function' 145 and 'catalytic function' were clustered in Molecular Function; two sub categories of 'cell' and 146 'cell part' were clustered in Cellular Component and the details are provided in the 147 Supplementary Table S2. There is only 65 number of CA-MRSA Bioproject is available in the 148 NCBI data (www.ncbi.nlm.nih.gov) and those were mainly from Healthcare Associated MRSA 149 (HA-MRSA), whereas no reports from the fishery environment are available and it is the first 150 kind of CA- MRSA in food fish of India. 
151

152

153

154

155

156

157

158

159

160

161

162

163

164

165

166

167

168

169

170

171

172

173

174

175

176

177

178

179

180

181

\section{Antimicrobial resistance pattern and ARGs by CARD Analysis of WGS}

Higher level of resistance to rifampicin (76 to 100\%), trimethoprim/sulfamethoxazole (69 to $81 \%$ ), linezolid (69 to $75 \%$ ), gentamicin (53-72\%), piperacillin-tazobactam (53 to $72 \%$ ), ampicillin/ sulbactam (23 to 37\%), cefoxitin (16\%), and ofloxacin (12 to 23\%) among these isolates from these fish samples were noticed (CLSI, 2018) and recognized as multidurg resistant strain (MDR) as they showed resistance to more than 3 classes of antibiotics. Complete susceptible to the following antibiotics such as azithromycin (AZM) 15 $\mu$ g, clarithromycin (CLR) $15 \mu \mathrm{g}$, ciprofloxacin (CIP) $5 \mu \mathrm{g}$, gatifloxacin (GAT) $5 \mu \mathrm{g}$, clindamycin (CD) $2 \mu \mathrm{g}$, tigecycline

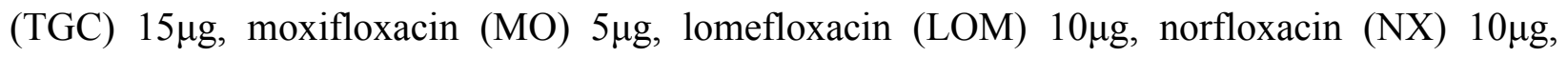

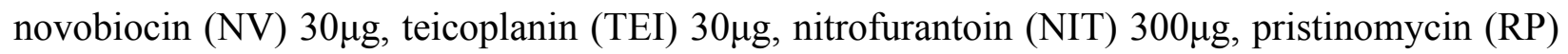
$15 \mu \mathrm{g}$ were observed.

The CARD is a rigorously curated collection of known resistance determinants and associated antibiotics, organized by the Antibiotic Resistance Ontology (ARO) and Antimicrobial Resistance (AMR) detection models at McMaster University (McArthur et al., 2013, Jia et al., 2017). Results revealed that 8 major ARO genes encoded for antimicrobial resistance such as $m e p \mathrm{R}, m g r \mathrm{~A}, \operatorname{arl\mathrm {R}}$ with perfect Resistance Gene Identifier (RGI) hit and S. aureus $\operatorname{lm} r \mathrm{~S}$, fosB, norA and G1pT mutation with strict RGI hit. This strain possessed these resistance genes to 12 drug classes viz., aminoglycoside antibiotic, cephalosporin, diaminopyrimidine, fluoroquinolone, fosfomycin, glycylcycline, macrolide, oxazolidinone, peptide, phenicol and tetracycline antibiotic and also for an acridine dye resistance through mechanisms such as antibiotic efflux, antibiotic inactivation and antibiotic target alteration. ARGs showed 100\% sequence similarity except S. aureus $\operatorname{LmrS}(96.67 \%)$ and S. aureus norA (95.62\%) as compared with the \% length of reference sequence (Table 1).

The isolate possessed the ARGs such as mepR for glycylcycline and tetracycline antibiotic, $m g r$ A for fluoroquinolone, cephalosporin, penam, tetracycline and peptide antibiotic, $\operatorname{ar} l \mathrm{R}$ for fluoroquinolone and acridine dyes, $\operatorname{lm} r \mathrm{~S}$ for macrolide, aminoglycoside, oxazolidinone, diaminopyrimidine and phenicol, fos $\mathrm{B}$ for fosfomycin, nor $\mathrm{A}$ for fluoroquinolone, glp $\mathrm{T}$ and murA transferase for $S$. aureus with mutation conferring resistance to fosfomycin resistance (Thompson et al., 2014, Fu et al., 2015, Lee et al., 2020). Raygada \& Levine, 2009 stated that most CA-MRSA were susceptible to doxycycline, minocycline, clindamycin, trimethoprim-sulfamethoxazole (TMP-SMX), chloramphenicol, rifampin, and linezolid. Whereas, the susceptibility to different 
182 antimicrobial agents were reported in varied ranges in different parts of the world (Dennis et al.,

183 2002, Ruhe et al., 2005, Diep et al., 2006, Kallen et al., 2007, Raygada \& Levine, 2009).

184 The three ARO genes mepR, $m g r \mathrm{~A}$, and $\operatorname{arl\mathrm {R}}$ were $100 \%$ identical to reference and aligned with $185100 \%$ coverage to the reference sequence. In addition, analysis of $S$. aureus glpT determining 186 fosfomycin resistance showed a point mutation which led to a higher level of resistance to 187 fosfomycin. The AMR genes analysed through CARD from the draft genome of MRSA7 strain 188 revealed that they arein correlation with the antimicrobial resistance profiles of disk diffusion 189 tests. Moreover, analysis of the draft genome sequences of this MRSA7 strain showed 190 methicillin resistance belonged to ST28/t021 and is highly resistant to oxazolidinone, 191 sulfonamide, cephems, fluroquinolones and aminoglycoside. In silico analysis revealed high 192 level of conservation in the AMR genes. A few reports from China documented the low 193 incidence of CA-MRSA with high proportionof multidrug resistance (Yao et al., 2010, Wang et 194 al., 2012). It is further suggested that the MDR ST28/t021 type of MRSA strain might have 195 acquired these AMR genes from the workers and possibly circulating in thisdried fish 196 environment. The phylogenetic trees are constructed based on the virulence genes and ARGs 197 (Supplementary figure S2 and S3). The Phylogenetic tree was constructed in NCBI with its data 198 base based on the relations between isolates to virulence genes and ARGs. Data are visualized as 199 minimum spanning tree (MST) and showed that methicillin resistant S. aureus (MRSA 7) strain 200 of this study are closely related to other $S$. aureus strains mainly MRSA strains in the NCBI data.

201

202

203

204

205

206

207

208

209

210

211

\section{Putative Virulence factors of CA- MRSA detection}

The VirulenceFinder v 2.0 analysis of the core-genome virulence factors MRSA7 strain revealed different virulent factors for cytotoxins, leukotoxins, lekocidins and superantigenic toxinsenterotoxins and virulence factor for exozyme genes such as aureolysin (aur) and serine protease (spiE) (Table 2).

The GOs virulence pathways mainly to the cationic antimicrobial peptide (CAMP) resistance, $S$. aureus infection (aureolysin) hemolysis by symbiont of host erythrocytes, extracellular component, pathogenesis, toxin activity (hemolysin), peptidase $\operatorname{deg} \mathrm{P}$ and htrA serine protease and GOs for ARGs are two- component system (arlR) for adhesion, autolysis, MDR and virulence genes, metallothioltransferase (fosB), chemical binding (LmrS), MATE family multidrug efflux pump (mepA), major facilitator superfamily (MFS) antibiotic efflux pump 
212 (mgrA, norA), N-acetylmuramic acid 6-phosphate etherase (murA) and MFS transporter, DHA2

213 family, multidrug resistance protein (norB and glpT). The virulence genes of MRSA included 214 gamma-hemolysin chain II precursor ( $h \lg \mathrm{A})$, gamma-hemolysin component B precursor $(h \lg \mathrm{B})$, 215 gamma- hemolysin component C (hlgC), Panton Valentine leukocidin F component (lukF-PV) 216 and Panton Valentine leukocidin S component (lukS-PV) with 100\% identity on its genes. The 217 presence of leukocidins- Panton-Valentine leukocidin (PVL) (LukS and LukF proteins) in this 218 MRSA7 strain may cause cytotoxicity to different leukocytes and macrophages and is reported to 219 be associated with CA-MRSAinfections. The present study revealed the presence of leukocidins220 Panton-Valentine leukocidin (PVL) (LukS and $L u k \mathrm{~F}$ proteins), reported to be associated with 221 CA-MRSA infections. The incidence of CA- MRSA in seafood was also reported (Sivaraman et 222 al., 2016). The hemolysins viz., $h \lg \mathrm{A}, h \operatorname{lgB}$ and $h l g \mathrm{C}$ are well known toxins to blood cells 223 causing cell lysis and cell death. Several reports documented the presence of increased virulence 224 factors in CA-MRSA (Novick \& Muir, 1999; Wang et al., 2007; Wardenburg et al., 2007; Li et 225 al., 2010; DeLeo et al., 2011; Hetem et al., 2012). CA-MRSA strains possess a varying 226 repertoire of virulence factors/ toxin genes mainly encoded on mobile genetic elements and 227 could be transferred between strains by horizontal gene transfer and recognized as a potential 228 pathogen.

Staphylococcus aureus are the most frequently occurring food-borne pathogens worldwide with the presence of heat stable preformed staphylococcal enterotoxins (Seo \& Bohach, 2007; FDA, 2012) and could cause foodborne intoxication with less than 1.0 microgram toxin from the contaminated food $(C D C, 2010)$. The WGS of this MRSA7 strain (S. aureus 55/2053) shows the presence of Staphylococcal enterotoxins (SEs) such as enterotoxin G (seg), enterotoxin I (sei), enterotoxin M (sem), enterotoxin $\mathrm{N}$ (sen), enterotoxin $\mathrm{O}$ (seo) and enterotoxin $\mathrm{U}$ (seu) with 99.87, 100, 99.86, 97.43, 100, and 100\% identity, respectively with the Accession number CP002388.1. S. aureus is considered to be one of the potential food-borne pathogens due to the presence of SEs: SEA to SEE, SEG to SEI, SER to SET (CDC, 2010; Argudin, Mendoza $\&$ Rodicio, 2010). SEs may cause vomiting and diarrhoea and the toxins are one of the most common causes of food-borne diseases. The toxins are secreted by entero-toxigenic S. aureus strains in food; they are heat-stable and are not degraded by cooking processes. The SEs are super antigens which trigger T-cell activation and proliferation; their mode of action probably 
243 includes activation of cytokine release and cell death via apoptosis and potentially lethal toxic

244 shock syndrome (Balaban \& Rasooly, 2000; Lin et al., 2010). This strain also harbours the

245 virulence factor for secreted exoenzyme genes such as aureolysin (aur) and serine protease

246 (spIE) with 100\% identity and accession numbers (CP009554.1 and BX571856.1), respectively

247 and they mainly interfere with host metabolic or signalling cascades. The protease aureolysin $(S$.

248 aureus neutral proteinase) cleaves many proteins including insulin B, with a preference of

249 cleaving after hydrophobic residue and also inactivates PSMs, which cause pathogenesis of 250 osteomyelitis (Larkin et al., 1982). Aureolysin, glutamylendopeptidase, and the cysteine 251 proteases staphopain A and B all interfere with complement factors, leading to evasion of 252 complement-mediated bacterial killing (Baliga et al., 2008). The exfoliative toxins-serine 253 proteases specifically cleave desmosomalcadherins of the superficial skin layers (Recsei et al., 254 1986; Amagai et al., 2000), leading to staphylococcal scalded skin syndrome (SSSS), a severe 255 skin disease presenting with rash, blisters, and severe lesional damage of the skin. Hence, the co256 existence of these different virulence factors for cytotoxins, leukotoxins, lekocidins and 257 superantigenic toxins- enterotoxins and for exozyme genes such as aureolysin (aur) and serine 258 protease (spiE), suggesting that MRSA7 strain may be of significant pathogenic of importance to 259 the public health.

\section{Spa typing and Multi Locus Sequence Typing (MLST)}

261 The availability of the spa types on the central spa server (http://spaserver.ridom.de) and its 262 unified nomenclature provide to understand clonal diversity and transmission of MRSA in the 263 hospital and community settings. The most common spa type in the strain was t021 and its 264 repeats are 15-12-16-02-16-02-25-17-24 in the position between 973-1226bp in the contig position of MRSA7_gen_1564. Ridom spa server https://spa.ridom.de/spa302 t021.shtml shows a total of 4568 strains with the frequencies of $1.06 \%$ with the comment on CA-MRSA (lukSlukF) with the CC30 and ST-30 and 3 spa types are reported in India.

MLST analysis of the total genome sequenced (NBZX00000000.1) revealed that MRSA7 strain typed to a ST 28 in fish and fishery products in India with arcC, aroE, glpF, gmk, pta, tpi, ygi $\mathrm{L}$ genes with $100 \%$ identity and coverage with the alleles of 46, 402, 9, 37, 67, 57, and 557, respectively (Table 3). In the present study, MRSA7 strain Type t021 represents so called ST 28 MRSA, which was found in the fish samples in Gujarat State, India. 
The earliest reportedCA-MRSA infections acquired from the communityin 1980 when

274 outbreaks of invasive infections occurred among the intravenous drug users in Detriot

275 (Saravolatz et al., 1982, Levine et al., 1986) and a unique CA-MRSA was isolated in Australia

276 among aborigines with the history of exposure to antibiotics in 1993. Then the incidence of CA-

277 MRSA was reported in different parts of the world, New Zealand, UK, France, Finland, Canada,

278 USA, and Asia. Major sequence types disseminated across the globe includes ST1, ST5, ST8,

279 ST15, ST30, ST59,ST72, ST80, ST88, ST93, ST121, ST152, ST188, ST398, ST508,ST728,

280 ST834, USA300, etc. (Sowash \& Uhlemann, 2014). There is a paucity of information on CA-

281 MRSA in Asian countries as compared to the Europe and USA due to lack of information on the

282 molecular epidemiology of $S$. aureus and detailed genotyping based on WGS. It is revealed that

283 a low burden of CA-MRSA except ST59 (Taiwan clone) in Taiwan, China and ST239 in South

284 Korea, Malaysia, China, India and Pakistan (Huang \& Chen, 2011). A number of studies from

285 India, mainly conducted at hospital centres, suggestedrelatively high prevalence of MRSA, but

286 the contribution of CA-MRSA to S. aureus infections is less clear. To date, strains ST22 and

287 ST772 have been identified as major CA-MRSA clones among infectious isolates and the 288 incidences reported were very low (D'Souza, Rodrigues \& Mehta, 2010). However, no report of 289 CA- MRSA in fish is available in India and this is to be a first of its kind based on WGS 290 analysis.

A human pandemic community-associated CC97 lineage MRSA harbouring the antimicrobial resistance genes $m e c \mathrm{~A}$ and $m e c \mathrm{C}$ has been shown to have originated from animals 293 (Chon Sung \& Khan, 2017).However, in most of the cases reported, a single risk factor could not be ruled out. The presence of MRSA ST28/t021 with luk genes, virulence genes and ARGs in fish is the first kind of report from India. Further comparative genomic analysis provide insights to understand the genetic background information namely genetic structure, dissemination, emergence, genomic diversity of this CA-MRSA strain on virulence, antibiotic resistance. This would further help in the control of such serious public health concern pathogen through the implementation of strict antimicrobial stewardship programme at the local and national level.

300

301

302 303

\section{Nucleotide Sequence Accession Number}

The draft genome sequence of the MRSA7 strain was submitted in the NCBI GenBank under the accession number NBZX00000000. 
304

305

306

307

308

309

310

311

312

313

314

315

316

317

318

319

320

321

322

323

324

325

326

327

328

329

330

\section{CONCLUSIONS}

A unique ST28/ t021 Community Associated MRSA in fish is the first report from India, and it co-harbors multi-antibiotic resistance and contains virulence genes, $l u k \mathrm{~S}-l u k \mathrm{~F}$, haemolysins, aureolysins and endotoxins. Future studies involving the comparative genomic analysis of CAMRSA strain7 will help further understand the diversity, virulence and endotoxicity of Staphylococcus in fish.

\section{ACKNOWLEDGEMENTS}

The Scientists and technical staffs of the lab are duly acknowledged.

\section{ADDITIONAL INFORMATION AND DECLARATIONS}

\section{Funding}

Funding was provided by The DG, DARE, New Delhi, India and Director, ICAR- Central Institute of Fisheries Technology (CIFT), Kochi, India, and work was carried out under the Institute ad-hoc project. The funders had no role in study design, data collection and analysis, decision to publish, or preparation of the manuscript

\section{Competing interests}

The authors declare there are no competing interests

\section{Author contributions}

G.K Sivaraman planned, carried out the PCR confirmation and drafted the manuscript, Visnuvinayagam S performed the laboratory works and bacterial identification, Balasubramanian G analyzed the WGS and suggested for write up of the manuscript, Ardhra V assisted in the compilation and checking the manuscript and M. M. Prasad corrected and analysed the works.

\section{REFERENCES}

Alcock BP, Raphenya AR, Lau TT, Tsang KK, Bouchard M, Edalatmand A, Huynh W, Nguyen AL, Cheng AA, Liu S, Min SY.2020.CARD 2020: antibiotic resistome 
331

332

333

334

335

336

337

338

339

340

341

342

343

344

345

346

347

348

349

350

351

352

353

354

355

356

357

358

359

360

361

surveillance with the comprehensive antibiotic resistance database. Nucleic acids research48:517-525DOI:https://doi.org/10.1093/nar/gkz935

Al-Talib H, Yean CY, Al-Khateeb A, Hassan H, Singh KK, Al-Jashamy K, Ravichandran M. 2009. A pentaplex $P C R$ assay for the rapid detection of methicillin-resistant Staphylococcus aureus and Panton-Valentine Leucocidin. BMC microbiology9(1):113DOI:https://doi.org/10.1186/1471-2180-9-113

Amagai M, Matsuyoshi N, Wang ZH, Andl C, Stanley JR.2000. Toxin in bullous impetigo and staphylococcal scalded-skin syndrome targets desmoglein 1. Nature medicine6(11):1275-1277 DOI:https://doi.org/10.1038/81385

Argudín MÁ, Mendoza MC, Rodicio MR. 2010. Food poisoning and Staphylococcus aureus enterotoxins. Toxins2(7):1751-1773. DOI:https://doi.org/10.3390/toxins2071751

Balaban N, Rasooly A.2000. Staphylococcal enterotoxins. International journal of food microbiology61(1):1-10DOI:https://doi.org/10.1016/S0168-1605(00)00377-9

Baliga S, Bansil R, Suchitra U, Bharati B, Vidyalakshmi K, Shenoy S. 2008. Nasal carriage of meticillin-resistant Staphylococcus aureus in medical students. Journal of Hospital Infection68(1):91-92DOI:https://doi.org/10.1016/j.jhin.2007.10.008

CDC (Centers for Disease Control and Prevention), Atlanta, GA, USA 2010. Staphylococcal food poisoning.http://www.cdc.gov/dfbmd/diseases/staphylococcal/.

Chon J, Sung K, Khan S. 2017. Methicillin-resistant Staphylococcus aureus (MRSA) in foodproducing and companion animals and food products. Frontiers in Staphylococcus aureus. 8:47-102.

Clinical and Laboratory Standards Institute (CLSI). 2018. Performance standards for antimicrobial susceptibility testing. M100 $28^{\text {th }}$ edition. Wayne, PA

Coombs GW, Bell JM, Pearson JC, Collignon PJ, Nimmo GR, McLaws ML, Christiansen KJ.2009. Prevalence of MRSA strains among Staphylococcus aureus isolated from outpatients, 2006. Report from the Australian Group for Antimicrobial Resistance. Communicable diseases intelligence quarterly report 33(1): 10 .

Coombs GW, Goering RV, Chua KY, Monecke S, Howden BP, Stinear TP, Ehricht R, O'Brien FG, Christiansen KJ.2012. The molecular epidemiology of the highly virulent ST93 Australian community Staphylococcus aureus strain. PloS one7(8):43037DOI; https://doi.org/10.1371/journal.pone.0043037 
362

363

364

365

366

367

368

369

370

371

372

373

374

375

376

377

378

379

380

381

382

383

384

385

386

387

388

389

390

391

392

Delcher AL, Harmon D, Kasif S, White O, Salzberg SL. 1999. Improved microbial gene identification with GLIMMER. Nucleic Acids Res 27: 4636-4641. https://doi.org/10.1093/nar/27.23.4636.

DeLeo FR, Kennedy AD, Chen L, Wardenburg JB, Kobayashi SD, Mathema B, Braughton KR, Whitney AR, Villaruz AE, Martens CA, Porcella SF. 2011. Molecular differentiation of historic phage-type 80/81 and contemporary epidemic Staphylococcus aureus. Proceedings of the National Academy of Sciences108(44):1809118096DOI;https://doi.org/10.1073/pnas.1111084108

Dennis LS, Daniel H, Harry L, John LH, Donald HB, Barry H, 2002. Linezolid MRSA Study Group. Linezolid versus vancomycin for the treatment of methicillin-resistant Staphylococcus aureus infections. Clinical Infectious Diseases34(11):14811490.DOI:https://doi.org/10.1086/340353

Diep BA, Chan L, Tattevin P, Kajikawa O, Martin TR, Basuino L, Mai TT, Marbach H, Braughton KR, Whitney AR, Gardner DJ. 2010. Polymorphonuclear leukocytes mediate Staphylococcus aureus Panton-Valentine leukocidin-induced lung inflammation and injury. Proceedings of the National Academy of Sciences107(12):55875592DOI; https://doi.org/10.1073/pnas.0912403107

Diep BA, Gill SR, Chang RF, Phan TH, Chen JH, Davidson MG, Lin F, Lin J, Carleton HA, Mongodin EF, Sensabaugh GF.2006. Complete genome sequence of USA300, an epidemic clone of community-acquired meticillin-resistant Staphylococcus aureus. The Lancet367(9512):731-739DOI:https://doi.org/10.1016/S0140-6736(06)68231-7

D'Souza N, Rodrigues C, Mehta A. 2010.Molecular characterization of methicillin-resistant Staphylococcus aureus with emergence of epidemic clones of sequence type (ST) 22 and ST 772 in Mumbai, India. Journal of clinical microbiology48(5):18061811DOI: 10.1128/JCM.01867-09

FDA (Food and Drug Administration) 2012. Bad bug book: Foodborne pathogenic microorganisms and natural toxins handbook, 2nd ed. US Food and Drug Administration, Silver Spring 87-92.

Fu, Zhuyingjie, Ma Ying, Chen Chunhui, Guo Yan, Hu Fupin, Liu Yang, XuXiaogang and Wang Minggui. 2015. Prevalence of Fosfomycin Resistance and Mutations in murA, glpT, and uhpT in Methicillin-Resistant Staphylococcus aureus Strains Isolated from 
Blood and Cerebrospinal Fluid Samples, Front Microbiol. 2015; 6: 1544. doi: 10.3389/fmicb.2015.01544

\section{Gutiérrez D, Delgado S, Vázquez-Sánchez D, Martínez B, Cabo ML, Rodríguez A, Herrera} JJ, García P. 2012. Incidence of Staphylococcus aureus and analysis of associated bacterial communities on food industry surfaces. Appl Environ Microbiol 78:85478554. https://doi.org/10 .1128/AEM.02045-12.

Hetem DJ, Westh H, Boye K, Jarlov JO, Bonten MJ, Bootsma MC. 2012. Nosocomial transmission of community-associated methicillin-resistant Staphylococcus aureus in Danish Hospitals. Journal of Antimicrobial Chemotherapy67(7):17751780DOI:https://doi.org/10.1093/jac/dks125

Huang YC, Chen CJ.2011. Community-associated meticillin-resistant Staphylococcus aureus in children in Taiwan, 2000s. International journal of antimicrobial agents38(1):2-8. DOI:https://doi.org/10.1016/j.ijantimicag.2011.01.011

ISO (International Organisation for Standardization). (2003a, b \& c). ISO 6888-1: 2003 A1:2003

Jia B, Raphenya AR, Alcock B, Waglechner N, Guo P, Tsang KK, Lago BA, Dave BM, Pereira S, Sharma AN, Doshi S. 2016. CARD 2017: expansion and model-centric curation of the comprehensive antibiotic resistance database. Nucleic acids research45:566-573DOI:https://doi.org/10.1093/nar/gkw1004

Jones TF, Creech CB, Erwin P, Baird SG, Woron AM, Schaffner W. 2006. Family outbreaks of invasive community-associated methicillin-resistant Staphylococcus aureus infection. Clinical Infectious Diseases 42(9):76-78DOI;https://doi.org/10.1086/503265

Kallen AJ, Hageman J, Gorwitz R, Beekmann SE, Polgreen PM.2007. Characteristics of Staphylococcus aureus community-acquired pneumonia during the 2006-2007 influenza season. Clinical infectious diseases45(12):1655DOI:https://doi.org/10.1086/523721

Knox J, Uhlemann AC, Miller M, Hafer C, Vasquez G, Vavagiakis P, Shi Q, Lowy FD.2012. Environmental contamination as a risk factor for intra-household $\begin{array}{llll}\text { Staphylococcus aureus transmission. } & \text { PLoS }\end{array}$ One7(11)DOI; https://doi.org/10.1371/journal.pone.0049900

Larkin SM, Williams DN, Osterholm MT, Tofte RW, Posalaky Z.1982. Toxic shock syndrome: clinical, laboratory, and pathologic findings in nine fatal cases. Annals of internal medicine 96:858-864DOI:https://doi.org/10.7326/0003-4819-96-6-858 
424

425

426

427

428

429

430

431

432

433

434

435

436

437

438

439

440

441

442

443

444

445

446

447

448

449

450

451

452

Larsen MV, Cosentino S, Rasmussen S, Friis C, Hasman H, Marvig RL, Jelsbak L, Sicheritz-Pontén T, Ussery DW, Aarestrup FM, Lund O.2012. Multilocus sequence typing of total-genome-sequenced bacteria. Journal of clinical microbiology50(4):13551361DOI: 10.1128/JCM.06094-11

Lee, YC., Chen, PY., Wang, JT. et al.2020. Prevalence of fosfomycin resistance and gene mutations in clinical isolates of methicillin-resistant Staphylococcus aureus. Antimicrob Resist Infect Control 9, 135 (2020). https://doi.org/10.1186/s13756-020-00790-X

Levine DP, Crane LR, Zervos MJ.1986.Bacteremia in narcotic addicts at the Detroit Medical Center. II. Infectious endocarditis: a prospective comparative study. Rev Infect Dis. 8(3):374-96. doi: 10.1093/clinids/8.3.374. PMID: 3755255.

Li M, Cheung GY, Hu J, Wang D, Joo HS, DeLeo FR, Otto M. 2010. Comparative analysis of virulence and toxin expression of global community-associated methicillin-resistant Staphylococcus aureus strains. Journal of Infectious Diseases 202(12):18661876DOI;https://doi.org/10.1086/657419

Li M, Cheung GY, Hu J, Wang D, Joo HS, DeLeo FR, Otto M.2010. Comparative analysis of virulence and toxin expression of global community-associated methicillin-resistant Staphylococcus aureus strains. Journal of Infectious Diseases202(12):18661876DOI:https://doi.org/10.1086/657419

Lin CF, Chen CL, Huang WC, Cheng YL, Hsieh CY, Wang CY, Hong MY. 2010. Different types of cell death induced by enterotoxins. Toxins2(8):21582176.DOI:https://doi.org/10.3390/toxins2082158

McArthur AG, Waglechner N, Nizam F, Yan A, Azad MA, Baylay AJ, Bhullar K, Canova MJ, De Pascale G, Ejim L, Kalan L. 2013. The comprehensive antibiotic resistance database. Antimicrobial agents and chemotherapy57(7):33483357.DOI: 10.1128/AAC.00419-13

Nerby JM, Gorwitz R, Lesher L, Juni B, Jawahir S, Lynfield R, Harriman K. 2011. Risk factors for household transmission of community-associated methicillin-resistant Staphylococcus aureus. The Pediatric infectious disease journal30(11): 927932.DOI.10.1097/INF.0b013e31822256c3 
453 Novick RP, Muir TW.1999. Virulence gene regulation by peptides in staphylococci and other

454

455

456

457

458

459

460

461

462

463

464

465

466

467

468

469

470

471

472

473

474

475

476

477

478

479

480

481

482

Gram-positive bacteria. Current opinion in microbiology2(1):4045DOI;https://doi.org/10.1016/S1369-5274(99)80007-1

Queck SY, Jameson-Lee M, Villaruz AE, Bach TH, Khan BA, Sturdevant DE, Ricklefs SM, Li M, Otto M.2008. RNAIII-independent target gene control by the agr quorumsensing system: insight into the evolution of virulence regulation in Staphylococcusaureus. Molecular cell32(1):150-158 DOI;https://doi.org/10.1016/j.molcel.2008.08.005

Raygada JL, Levine DP. 2009. Methicillin-Resistant Staphylococcus aureus: A Growing Risk in the Hospital and in the Community. American health \& drug benefits 2(2):86-95

Recsei P, Kreiswirth B, O'reilly M, Schlievert PM, Gruss A, Novick RP.1986. Regulation of exoprotein gene expression in Staphylococcus aureus by agr. Molecular and General Genetics MGG 202(1):58-61DOI:https://doi.org/10.1007/BF00330517

Risson DC, O Connor ED, Guard RW, Schooneveldt JM, Nimmo GR.2007. A fatal case of necrotising pneumonia due to community-associated methicillin-resistant Staphylococcus aureus. Medical journal of Australia186(9):479.

Ruhe JJ, Monson T, Bradsher RW, Menon A. 2005. Use of long-acting tetracyclines for methicillin-resistant Staphylococcus aureus infections: case series and review of the literature. Clinical infectious diseases40(10):1429-1434. DOI:https://doi.org/10.1086/429628

Saravolatz LD, Markowitz N, Arking L, Pohlod D, Fisher E.1982. Methicillin-resistant Staphylococcus aureus. Epidemiologic observations during a community-acquired outbreak. Ann Intern Med. 1982 Jan;96(1):11-6. doi: 10.7326/0003-4819-96-1-11. PMID: 7053683.

Seo KS, Bohach GA.2007. Staphylococcus aureus. Food Microbiology3:493-518.

Sivaraman, G.K., Vanik, D., Visnuvinayagam, S., Prasad, M.M. and Ravishankar, C.N., 2017. Draft Genome Sequence of a Methicillin-Resistant Staphylococcus aureus Isolate (Sequence Type 1) from Seafood. Genome Announcements 5(34).

Sivaraman GK, Deesha V, Prasad MM, Jha AK, Vishnuvinayagam S, Nadella RK, Chandni V, Basha A. 2016. Incidence of community acquired methicillin-resistant 
483

484

485

486

487

488

489

490

491

492

493

494

495

496

497

498

499

500

501

502

503

504

505

506

507

508

509

510

511

512

513

Staphylococcus aureus (CA-MRSA) in seafood and its environment, Gujarat, India. International Journal of Recent Scientific Research7:14279-14282.

Sowash MG, Uhlemann AC. 2014. Community-associated methicillin-resistant Staphylococcus aureus case studies. Methods Molecular Biology1085:25-69 DOI:https://doi.org/10.1007/978-1-62703-664-12

Talan DA, Krishnadasan A, Gorwitz RJ, Fosheim GE, Limbago B, Albrecht V, Moran GJ.2011. Comparison of Staphylococcus aureus from skin and soft-tissue infections in US emergency department patients, 2004 and 2008. Clinical infectious diseases53(2):144-149DOI:https://doi.org/10.1093/cid/cir308

Wang L, Liu Y, Yang Y, Huang G, Wang C, Deng L, Zheng Y, Fu Z, Li C, Shang Y, Zhao C.2012. Multidrug-resistant clones of community-associated meticillin-resistant Staphylococcus aureus isolated from Chinese children and the resistance genes to clindamycin and mupirocin. Journal of medical microbiology61(9):12401247DOI:https://doi.org/10.1099/jmm.0.042663-0

Wang R, Braughton KR, Kretschmer D, Bach TH, Queck SY, Li M, Kennedy AD, Dorward DW, Klebanoff SJ, Peschel A, DeLeo FR.2007. Identification of novel cytolytic peptides as key virulence determinants for community-associated MRSA. Nature medicine13(12):1510-1514DOI;https://doi.org/10.1038/nm1656

Wardenburg JB, Bae T, Otto M, DeLeo FR, Schneewind 0.2007. Poring over pores: $\alpha$ hemolysin and Panton-Valentine leukocidin in Staphylococcus aureus pneumonia. Nature medicine13(12):1405-1406DOI;https://doi.org/10.1038/nm1207-1405

Wardenburg JB, Bae T, Otto M, DeLeo FR, Schneewind 0.2007. Poring over pores: $\alpha$ hemolysin and Panton-Valentine leukocidin in Staphylococcus aureus pneumonia. Nature medicine 13(12):1405-1406DOI:https://doi.org/10.1038/nm1207-1405

Yao D, Yu FY, Qin ZQ, Chen C, He SS, Chen ZQ, Zhang XQ, Wang LX.2010. Molecular characterization of Staphylococcus aureus isolates causing skin and soft tissue infections (SSTIs). BMC Infectious Diseases10(1):1-5. DOI:https://doi.org/10.1186/1471-2334-10$\underline{133}$

Zimin AV, Marçais G, Puiu D, Roberts M, Salzberg SL, Yorke JA. 2013. The MaSuRCA genome assembler. $\quad$ Bioinformatics29:2669 $-2677 . \quad \mathrm{https} / / \mathrm{doi}$ .org/10.1093/bioinformatics/btt476. 


\section{Figure 1}

Figure 1: Biological, Molecular and Cellular function category components function category from $\mathrm{GO}$ of annotation
A) Top 15 in terms of Biological function category from GO of annotation by BLAST2GO
software, B) Top 15 in terms of Molecular function category from GO of annotation, C) Top 15
in terms of Cellular Component function category from GO of annotation 

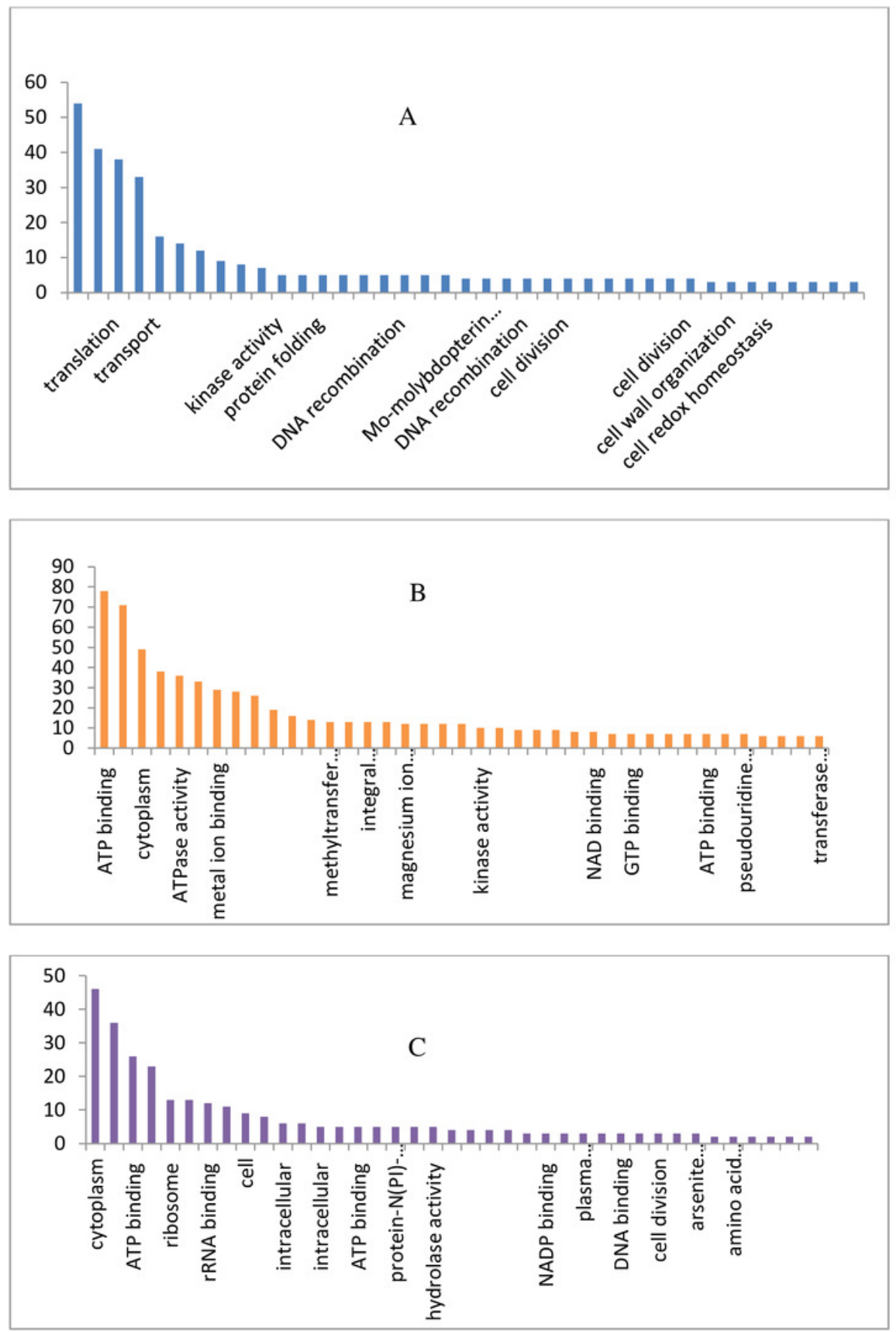

Figure 1 (A) Top 15 in terms of Biological function category, (B) Molecular function and (C) Cellular components from GO of annotation by BLAST2GO software; $Y$ axis: Number of ORFs 


\section{Table $\mathbf{1}$ (on next page)}

Antimicrobial resistance pattern and ARGs of MRSA7 strain using Comprehensive Antibiotic Resistance database (CARD) Analysis of WGS 
1 Table 1:

2 Antimicrobial resistance pattern and ARGs of MRSA7 strain using Comprehensive Antibiotic Resistance database (CARD)

3 Analysis of WGS

\begin{tabular}{|c|c|c|c|c|c|c|}
\hline RGI Criteria & ARO & AMR gene family & Drug class & $\begin{array}{l}\text { Resistance } \\
\text { Mechanism }\end{array}$ & $\begin{array}{l}\% \text { identity } \\
\text { of matching } \\
\text { regions }\end{array}$ & $\begin{array}{l}\text { \%Length of } \\
\text { reference } \\
\text { sequence }\end{array}$ \\
\hline Perfect & mep $\mathrm{R}$ & $\begin{array}{l}\text { Multidrug and toxic } \\
\text { compound extrusion } \\
\text { (MATE) transporter }\end{array}$ & Glycylcycline-tetracycline & $\begin{array}{l}\text { Antibiotic } \\
\text { efflux }\end{array}$ & 100.0 & 100.0 \\
\hline Perfect & $m g r \mathrm{~A}$ & $\begin{array}{l}\text { ATP- binding cassette } \\
\text { (ABC) antibiotic efflux } \\
\text { pump, major facilitator } \\
\text { superfamily (MFS) } \\
\text { antibiotic efflux pump }\end{array}$ & $\begin{array}{l}\text { Fluoroquinolone, } \\
\text { cephalosporin, penam, } \\
\text { tetracycline, peptide } \\
\text { antibiotic, acridine dye }\end{array}$ & $\begin{array}{l}\text { Antibiotic } \\
\text { efflux }\end{array}$ & 100.0 & 100.0 \\
\hline Perfect & $\operatorname{arl} \mathrm{R}$ & $\begin{array}{l}\text { Major facilitator } \\
\text { superfamily (MFS) } \\
\text { antibiotic efflux pump }\end{array}$ & $\begin{array}{l}\text { Fluoroquinolone } \\
\text { antibiotic }\end{array}$ & $\begin{array}{l}\text { Antibiotic } \\
\text { efflux }\end{array}$ & 100.0 & 100.0 \\
\hline Strict & $\begin{array}{l}\text { S. aureus } \\
\text { LmrS }\end{array}$ & $\begin{array}{l}\text { Major facilitator } \\
\text { superfamily (MFS) } \\
\text { antibiotic efflux pump }\end{array}$ & $\begin{array}{l}\text { macrolide, } \\
\text { aminoglycoside, } \\
\text { oxazolidinon, } \\
\text { diaminopyrimidine, \& } \\
\text { phenicol }\end{array}$ & $\begin{array}{l}\text { Antibiotic } \\
\text { efflux }\end{array}$ & 96.67 & 100.21 \\
\hline Strict & $\begin{array}{l}\text { S. aureus } \\
\text { FosB }\end{array}$ & Fofomycin thiol transferase & Fosfomycin & $\begin{array}{l}\text { Aibiotic } \\
\text { inacivation }\end{array}$ & 99.28 & 100.00 \\
\hline Strict & $\begin{array}{l}\text { S. aureus } \\
\text { norA }\end{array}$ & $\begin{array}{l}\text { Major facilitator } \\
\text { superfamily (MFS) } \\
\text { antibiotic efflux pump }\end{array}$ & $\begin{array}{l}\text { Fluoroquinolone } \\
\text { antibiotic }\end{array}$ & $\begin{array}{l}\text { Antibiotic } \\
\text { efflux }\end{array}$ & 95.62 & 100.00 \\
\hline
\end{tabular}




\begin{tabular}{|c|l|l|l|l|l|}
\hline Strict & $\begin{array}{l}\text { S. aureus } \\
\text { GlpT with } \\
\text { mutation } \\
\text { conferring } \\
\text { resistance to } \\
\text { fosfomycin }\end{array}$ & Antibiotic resistant GlpT & Fosfomycin & $\begin{array}{l}\text { Antibiotic } \\
\text { target } \\
\text { alteration }\end{array}$ & 100.0 \\
\hline Strict & $\begin{array}{l}\text { S. aureus } \\
\text { murA with } \\
\text { mutation } \\
\text { conferring } \\
\text { resistance to } \\
\text { fosfomycin }\end{array}$ & $\begin{array}{l}\text { Antibiotic-resistant } \text { murA } \\
\text { transferase }\end{array}$ & Fosfomycin & $\begin{array}{l}\text { Antibiotic } \\
\text { target } \\
\text { alteration }\end{array}$ & 100.00 \\
\hline
\end{tabular}




\section{Table 2 (on next page)}

Putative Virulence factors of CA- MRSA detection using VirulenceFinder-2.0 Server 
1 Table 1: Putative Virulence factors of CA- MRSA detection using VirulenceFinder-2.0

2 Server

\begin{tabular}{|c|c|c|c|c|c|c|}
\hline $\begin{array}{l}\text { Virulen } \\
\text { ce } \\
\text { factor }\end{array}$ & $\begin{array}{l}\text { Iden } \\
\text { tity }\end{array}$ & $\begin{array}{l}\text { Query / } \\
\text { Template } \\
\text { length }\end{array}$ & Contig & $\begin{array}{l}\text { Position } \\
\text { in } \\
\text { contig }\end{array}$ & Protein function & $\begin{array}{l}\text { Accessi } \\
\text { on } \\
\text { numbe } \\
\text { r }\end{array}$ \\
\hline$h \lg \mathrm{A}$ & 100 & $930 / 930$ & MRSA7_Gene_472 & $37 . .966$ & $\begin{array}{l}\text { gamma-hemolysin } \\
\text { chain II precursor }\end{array}$ & $\frac{\mathrm{CP} 0095}{\underline{54.1}}$ \\
\hline$h \lg \mathrm{A}$ & 100 & $930 / 930$ & MRSA7_Gene_472 & $37 . .966$ & $\begin{array}{l}\text { gamma-hemolysin } \\
\text { chain II precursor }\end{array}$ & $\frac{\text { LN626 }}{917.1}$ \\
\hline$h \lg \mathrm{B}$ & 100 & 978 / 978 & MRSA7_Gene_474 & $1 . .978$ & $\begin{array}{l}\text { gamma-hemolysin } \\
\text { component B } \\
\text { precursor }\end{array}$ & $\underline{\mathrm{BX} 571} \underline{\underline{856.1}}$ \\
\hline$h \lg \mathrm{C}$ & 100 & 948 / 948 & MRSA7_Gene_473 & $1 . .948$ & $\begin{array}{l}\text { gamma-hemolysin } \\
\text { component } \mathrm{C}\end{array}$ & $\begin{array}{l}\text { CP0095 } \\
54.1\end{array}$ \\
\hline$l u k \mathrm{~F}-\mathrm{PV}$ & 100 & 978 / 978 & $\begin{array}{l}\text { MRSA7_Gene_130 } \\
6\end{array}$ & $1 . .978$ & $\begin{array}{l}\text { Panton Valentine } \\
\text { leukocidin F } \\
\text { component }\end{array}$ & $\frac{\mathrm{AB} 678}{\underline{716.1}}$ \\
\hline$l u k \mathrm{~F}-\mathrm{PV}$ & 100 & 978 / 978 & $\begin{array}{l}\text { MRSA7_Gene_130 } \\
6\end{array}$ & $1 . .978$ & $\begin{array}{l}\text { Panton Valentine } \\
\text { leukocidin F } \\
\text { component }\end{array}$ & $\frac{\mathrm{HM} 584}{\underline{704.1}}$ \\
\hline lukS-PV & 100 & 939 / 939 & $\begin{array}{l}\text { MRSA7_Gene_130 } \\
5\end{array}$ & $1 . .939$ & $\begin{array}{l}\text { Panton Valentine } \\
\text { leukocidin S } \\
\text { component }\end{array}$ & $\frac{\mathrm{AB} 045}{\underline{978.2}}$ \\
\hline lukS-PV & 100 & 939 / 939 & $\begin{array}{l}\text { MRSA7_Gene_130 } \\
5\end{array}$ & $1 . .939$ & $\begin{array}{l}\text { Panton Valentine } \\
\text { leukocidin S } \\
\text { component }\end{array}$ & $\frac{\mathrm{AB} 256}{\underline{039.1}}$ \\
\hline seg & $\begin{array}{l}99.8 \\
7\end{array}$ & $778 / 778$ & $\begin{array}{l}\text { MRSA7_Gene_232 } \\
6\end{array}$ & $1 . .777$ & enterotoxin $\mathrm{G}$ & $\begin{array}{l}\text { CP0023 } \\
\underline{88.1}\end{array}$ \\
\hline sei & 100 & $729 / 729$ & $\begin{array}{l}\text { MRSA7_Gene_232 } \\
9\end{array}$ & $1 . .729$ & enterotoxin I & $\frac{\mathrm{CP} 0023}{\underline{88.1}}$ \\
\hline sem & $\begin{array}{l}99.8 \\
6\end{array}$ & $720 / 720$ & $\begin{array}{l}\text { MRSA7_Gene_233 } \\
0\end{array}$ & $1 . .720$ & enterotoxin $\mathrm{M}$ & $\begin{array}{l}\text { CP0023 } \\
\underline{88.1}\end{array}$ \\
\hline sen & $\begin{array}{l}97.4 \\
9\end{array}$ & $756 / 777$ & $\begin{array}{l}\text { MRSA7_Gene_232 } \\
7\end{array}$ & $1 . .756$ & enterotoxin $\mathrm{N}$ & $\frac{\mathrm{AP} 014}{\underline{653.1}}$ \\
\hline
\end{tabular}




\begin{tabular}{|l|l|l|l|l|l|l|}
\hline seo & 100 & $765 / 765$ & $\begin{array}{l}\text { MRSA7_Gene_233 } \\
1\end{array}$ & $1 . .765$ & enterotoxin O & $\underline{\underline{\mathrm{CP0023}}}$ \\
\hline seu & 100 & $786 / 786$ & $\begin{array}{l}\text { MRSA7_Gene_232 } \\
8\end{array}$ & $1 . .786$ & enterotoxin U & $\underline{\underline{\mathrm{CP0023}}}$ \\
\hline aur & 100 & $\begin{array}{l}1530 / \\
1530\end{array}$ & $\begin{array}{l}\text { MRSA7_Gene_180 } \\
2\end{array}$ & $1 . .1530$ & aureolysin & $\underline{\underline{\mathrm{CP} 0095}}$ \\
\hline splE & 100 & $717 / 717$ & $\begin{array}{l}\text { MRSA7_Gene_231 } \\
6\end{array}$ & $1 . .717$ & $\begin{array}{l}\text { serine protease } \\
\text { splE }\end{array}$ & $\underline{\underline{\mathrm{BX}}}$ \\
\hline
\end{tabular}

3 
Table 3(on next page)

Multi Locus Sequence Typing (MLST) analysis of the total genome sequenced (NBZX00000000.1) in MRSA Novel Sequence Type 243 


\section{Table 3:}

2 Multi Locus Sequence Typing (MLST) analysis of the total genome sequenced

3 (NBZX00000000.1) in MRSA Novel Sequence Type 28

\begin{tabular}{|c|l|l|l|l|l|l|}
\hline Locus & Identity & Coverage & $\begin{array}{l}\text { Alignment } \\
\text { Length }\end{array}$ & $\begin{array}{l}\text { Allele } \\
\text { Length }\end{array}$ & Gaps & Allele \\
\hline arcC & 100 & 100 & 456 & 456 & 0 & arcC_46 \\
\hline aroE & 100 & 100 & 456 & 456 & 0 & aroE_402 \\
\hline glpF & 100 & 100 & 465 & 465 & 0 & glpF_9 \\
\hline gmk & 100 & 100 & 417 & 417 & 0 & gmk_37 \\
\hline pta & 100 & 100 & 474 & 474 & 0 & pta_67 \\
\hline tpi & 100 & 100 & 402 & 402 & 0 & tpi_57 \\
\hline yqiL & 100 & 100 & 516 & 516 & 0 & yqiL_557 \\
\hline
\end{tabular}

4 